\title{
CONSERVAÇÃO DE SEMENTES DE IPÊ-ROXO (Tabebuia impetiginosa (Mart. ex DC.) Standl.) EM NITROGÊNIO LÍQUIDO ${ }^{1}$
}

\author{
LEILA MARTINS ${ }^{2}$, ANTÔNIO AUGUSTO DO LAGO³, ANTÔNIO CARLOS SILVA DE ANDRADE ${ }^{4}$, \\ WILSON ROBERTO MARQUES SALES ${ }^{5}$
}

\begin{abstract}
RESUMO - O ipê-roxo (Tabebuia impetiginosa (Mart. ex DC.) Standl.) é espécie de alto valor econômico, ornamental e medicinal e está na relação das espécies para conservação genética ex situ, no Instituto Florestal de São Paulo. O objetivo deste trabalho foi o de estudar o comportamento fisiológico de sementes de ipê-roxo, conservadas com diferentes teores de água em nitrogênio líquido, por 360 dias. Frutos maduros foram colocados sobre bancada de alvenaria, em interior de laboratório e sob luz indireta, para posterior extração manual das sementes. Primeiramente, foi determinado o grau de umidade do lote e obtida a amostra do tratamento controle, com o maior teor de água a ser estudado (18,3\%). Em seguida, as sementes remanescentes foram submetidas à secagem, em secador com circulação de ar a $30^{\circ} \mathrm{C}$, para a obtenção dos demais tratamentos $(12,5,8,4$ e $4,2 \%$ de água). Amostras de sementes de cada um dos teores de água foram armazenadas em nitrogênio líquido $\left(-196^{\circ} \mathrm{C}\right)$, sendo submetidas às avaliações fisiológicas no início e após 120, 240 e 360 dias de armazenamento. O delineamento experimental foi o inteiramente casualizado com quatro tratamentos (graus de umidade), avaliados separadamente para cada época de armazenamento. A comparação das médias foi realizada pelo teste Tukey, a 5\% de probabilidade. As sementes de ipê-roxo podem ser previamente desidratadas a baixo teor de água $(4,2 \%)$ e, posteriormente, conservadas em nitrogênio líquido por, pelo menos, 360 dias.
\end{abstract}

Termos para indexação: Tabebuia sp., armazenamento, banco de germoplasma, qualidade fisiológica.

\section{PRESERVATION OF Tabebuia impetiginosa (Mart. ex DC.) Standl. SEEDS IN LIQUID NITROGEN}

\begin{abstract}
Tabebuia impetiginosa is a tree of high economic, ornamental and medicinal value and is presently on the list of the Forest Institute of São Paulo as a species in need of genetic preservation ex situ. Thus, the objective of this research was to study the physiological performance of T. impetiginosa seeds with different moisture contents and storage in liquid nitrogen for 360 days. Mature fruits were placed under shade in the laboratory to allow hand seed extraction. The initial moisture content of the seed lot was then determined and a portion of it was removed that had the
\end{abstract}

${ }^{1}$ Submetido em 11/03/2008. Aceito para publicação em 19/09/2008. Apoiado financeiramente pela Fundação de Amparo à Pesquisa do Estado de São Paulo (FAPESP).

${ }^{2}$ Laboratório Central de Sementes e Mudas, Departamento de Sementes Mudas e Matrizes - CATI. Caixa Postal 962, CEP 13070-178, Campinas, SP, Brasil, email: leila@cati.sp.gov.br, bolsista do CNPq.

${ }^{3}$ Instituto Agronômico de Campinas/APTA. Caixa Postal 28, CEP 13001-
970, Campinas, SP, Brasil, email: aalago@iac.sp.gov.br

${ }^{4}$ Laboratório de Sementes - DIPEQ, Instituto de Pesquisas Jardim Botânico do Rio de Janeiro, Rua Pacheco Leão, 915 - Horto - Rio de Janeiro, RJ, Brasil, email: candrade@jbrj.gov.br

${ }^{5}$ Núcleo de Produção de Mudas de Pederneiras, Departamento de Sementes Mudas e Matrizes - CATI. Estrada Velha de Jaú, s/nº, Bairro Duas Passagens, Pederneiras, SP, Brasil, email: npm.pederneiras@cati.sp.gov.br 
highest degree of moisture (treatment) to be studied, which was $18.3 \%$. The remaining seeds were submitted to drying in a forced air circulation dryer at $30^{\circ} \mathrm{C}$ in order to obtain the other degrees of moisture $(12.5,8.4$ and $4.2 \%)$. The seed portions corresponding to the four moisture contents were stored in liquid nitrogen $\left(-196^{\circ} \mathrm{C}\right)$. They were submitted to physiological evaluations at $0,120,240$ and 360 days of storage. The experiment was set up in a randomized complete design, with four treatments (moisture degrees) and four replications; means were compared by the Tukey test at 5\%. T. impetiginosa seeds can be previously dried to a low degree of moisture $(4.2 \%)$ and preserved in liquid nitrogen for 360 days.

Index terms: Tabebuia sp, storage, germplasm bank, physiological quality

\section{INTRODUÇÃO}

Tabebuia impetiginosa (Mart. ex DC.) Standl., popularmente conhecida como ipê-roxo, pau d'arco-roxo, ipê-roxo-de-bola, entre outros, é uma Bignoniaceae de porte arbóreo, alcançando alturas de 8 a 20m, com característica de planta decídua (Lorenzi, 2002). É uma espécie secundária tardia a clímax, tolerando sombra no estádiojuvenil. Devido ao seu porte, faz parte do extrato superior da floresta, possuindo grande longevidade (Longhi, 1995). Sua ocorrência estendese desde o Estado do Piaú até o de São Paulo, tanto na floresta pluvial atlântica como na semidecídua (Lorenzi, 2002). É comum na vegetação secundária, abrangendo capoeiras e capoeirões (Longhi, 1995).

A espécie vem sendo estudada por ser de alto valor econômico, ornamental e medicinal e, principalmente, pela diminuição considerável do número de indivíduos encontrados em áreas de ocorrência natural (Ettori et al., 1996). Além disso, corre risco de extinção, estando na relação das espécies para conservação genética ex situ no Instituto Florestal de São Paulo (Siqueira e Nogueira, 1992).

Entende-se por criopreservação, o procedimento utilizado para a conservação de germoplasma em longo prazo (IBPGR, 1982), com o acondicionamento de material biológico a temperaturas ultra-baixas em nitrogênio líquido $\left(-196^{\circ} \mathrm{C}\right)$ ou em vapor $\left(-180^{\circ} \mathrm{C}\right)$. Nessas temperaturas, o metabolismo celular e os processos bioquímicos são substancialmente reduzidos e a deterioração biológica é paralisada (Kartha, 1985), consequentemente, é mínima a deterioração biológica do material durante o armazenamento.

$\mathrm{Na}$ última década, o avanço significativo nas pesquisas utilizando as técnicas de criopreservação de sementes, resultou em protocolos de conservação para cerca de 100 espécies. Entretanto, a maioria dos estudos envolveu sementes de espécies de clima temperado e frio e pouco foi realizado com as espécies de clima tropical e subtropical. Wetzel et al. (2003) consideram que a criopreservação de sementes pode ser considerada uma maneira de se preservar a biodiversidade dessas espécies no país.

A semente é a forma pela qual a planta sobrevive o máximo de tempo com o mínimo de atividade fisiológica. De acordo com Harrington (1972), o teor de água das sementes durante a conservação é um dos fatores que mais influencia a longevidade e um armazenamento eficaz está relacionado com a desidratação. Dessa forma, o período de viabilidade de sementes é função, dentre outros fatores, do teor de água da semente e da temperatura do armazenamento (Bewley e Black, 1984).

Reis e Cunha (1997), estudando o efeito do congelamento sobre a viabilidade de sementes de angico-vermelho (Anadenanthera peregrina (L.) Speg.), verificaram que o melhor desempenho foi o das sementes com $8,24 \%$ de água e armazenadas em nitrogênio líquido, em relação aos demais tratamentos (sementes com 5,56\%; 4,37\% e 3,51\% de água).

O objetivo deste trabalho foi o de estudar o comportamento fisiológico de sementes de ipê-roxo com diferentes teores de água, imersas em nitrogênio liquido a $-196^{\circ} \mathrm{C}$, durante o armazenamento por 360 dias.

\section{MATERIAL E MÉTODOS}

A pesquisa foi realizada no Laboratório Central de Sementes e Mudas do Departamento de Sementes, Mudas e Matrizes (LCSM/DSMM) da Coordenadoria de Assistência Técnica Integral (CATI), em Campinas. As sementes de ipê-roxo (Tabebuia impetiginosa (Mart. ex DC.) Standl.) 
foram provenientes do Núcleo de Produção de Mudas de Pederneiras - DSMM/CATI.

Os frutos de ipê-roxo foram colhidos maduros, porém ainda fechados, de seis plantas matrizes localizadas no município de Pederneiras, no Estado de São Paulo e colocados sobre bancada de alvenaria, em interior de laboratório e sob luz indireta, por $24 \mathrm{~h}$ para posterior extração manual das sementes. O grau de umidade inicial do lote foi determinado (BRASIL, 1992) e, paralelamente, obtida a amostra correspondente ao tratamento controle $(18,3 \%)$. Em seguida, as sementes remanescentes foram submetidas à secagem a $30^{\circ} \mathrm{C}$, em secador com circulação constante de ar, para a obtenção dos demais graus de umidade $(12,5 ; 8,4$ e $4,2 \%$ ). Esses teores foram definidos no intuito de estudar os efeitos da conservação de sementes em nitrogênio líquido, com teor de água muito alto $(18,3 \%)$, intermediários $(12,5 \%$ e $8,4 \%)$ e extremamente baixo $(4,2 \%)$.

Esses teores de água foram obtidos com acompanhamento da perda de massa das sementes durante a secagem. As amostras de sementes com massas iniciais previamente conhecidas foram acondicionadas em sacos de filó e distribuídas nas bandejas do secador para monitoramento da perda de massa a intervalos regulares. As massas finais das amostras, correspondentes aos graus de umidade desejados, foram calculadas por meio da equação de Cromarty et al. (1985):

$$
M_{f}=M_{i} \frac{\left(100-U_{i}\right)}{\left(100-U_{f}\right)}
$$

sendo:

$\mathrm{M}_{\mathrm{f}}=$ massa da amostra $(\mathrm{g})$ após a secagem;

$\mathrm{M}_{\mathrm{i}}=$ massa da amostra $(\mathrm{g})$ antes da secagem;

$\mathrm{U}_{\mathrm{i}}=$ grau de umidade (\%) antes da secagem;

$\mathrm{U}_{\mathrm{f}}=$ grau de umidade (\%) desejado após a secagem.

À medida que os graus de umidade estavam próximos dos desejados, as amostras foram retiradas, homogeneizadas, divididas em frações, embaladas em sacos de polietileno $\left(0,14 \mathrm{~mm}\right.$ de espessura) e mantidas a $20^{\circ} \mathrm{C} \pm 2^{\circ} \mathrm{C}$, provisoriamente, até a obtenção de todos os tratamentos, o que ocorreu após um, quatro e nove dias de secagem, respectivamente.

As amostras, correspondentes aos diferentes graus de umidade, foram armazenadas em nitrogênio líquido $\left(-196^{\circ} \mathrm{C}\right)$. Inicialmente as sementes foram submetidas à determinação do grau de umidade pelo método da estufa a $105 \pm 3^{\circ} \mathrm{C} / 24 \mathrm{~h}$ (BRASIL, 1992), com duas amostras de $1 \mathrm{~g}$ por tratamento. Os resultados obtidos, com base na massa úmida, foram expressos em porcentagem.

Antes do armazenamento e após este aos 120, 240 e 360 dias, foram realizadas as seguintes avaliações:

a) Teste de germinação: 120 sementes (seis subamostras de 20 sementes) foram dispostas em substrato de papel na forma de rolo (Stockman et al., 2007), mantidas em germinador tipo BOD a $25^{\circ} \mathrm{C}$ e foto período diário de $8 \mathrm{~h}$. O substrato foi umedecido com volume de água equivalente a três vezes a sua massa sem hidratação. As avaliações aos 11, 16 e 28 dias após a instalação do teste, forneceram dados expressos em porcentagem de plântulas normais (ISTA, 2007).

b) Emergência das plântulas: 120 sementes (seis subamostras de 20 sementes) foram semeadas entre areia $(0,5 \mathrm{~cm}$ de profundidade), autoclavada a $120^{\circ} \mathrm{C}$ por $2 \mathrm{~h}$, e disposta em caixas transparentes $(11 \times 11 \times 3,5 \mathrm{~cm})$, de plástico e sem tampa. As caixas foram distribuídas sobre bancada de alvenaria, em interior de laboratório e sob luz indireta, com temperatura e umidade relativa variáveis e sem o monitoramento destas. O substrato foi umedecido a aproximadamente $60 \%$ da capacidade de retenção de água (Marcos Filho et al., 1987). Foram consideradas plântulas normais as que após 30 dias da instalação do teste apresentaram a parte área exposta acima da superfície do substrato (Martins et al., 2007).

c) Velocidade de emergência das plântulas: obtida contando-se o número diário de indivíduos emersos no teste de emergência das plântulas, e calculando-se o índice (IVE) seguindo os procedimentos descritos por Maguire (1962) e Marcos Filho et al. (1987).

d) Comprimento do hipocótilo: determinado aos 30 dias após a instalação do teste de emergência, quando foi tomado o comprimento $(\mathrm{cm})$ das plântulas normais entre a região de transição da raiz-hipocótilo com a região de inserção das folhas cotiledonares. Os dados médios foram obtidos pelo quociente entre o somatório das medidas registradas em cada determinação e o número de sementes utilizadas, conforme recomendações de Vanzolini et al. (2007).

O delineamento experimental foi o inteiramente casualizado, com quatro tratamentos (graus de umidade) e seis repetições, em cada época de avaliação. A comparação das médias foi realizada pelo teste Tukey em nível de 5\% de probabilidade. Os dados de germinação e emergência de plântulas foram transformados em arcoseno $\sqrt{\mathrm{x} / 100}$, em que $x$ refere-se à porcentagem de germinação ou de emergência de plântulas, mas nas tabelas são apresentadas as médias sem transformação (\%).

\section{RESULTADOS E DISCUSSÃO}

As avaliações realizadas no início do armazenamento 
(germinação, emergência, índice de velocidade de emergência e comprimento da parte aérea da plântula) indicam que a dessecação das sementes não gerou efeitos imediatos e negativos à qualidade fisiológica (Tabela 1).

TABELA 1. Grau de umidade (GU), germinação (G), comprimento da parte aérea (CPA), índice de velocidade de emergência (IVE) e emergência (E) obtidas de sementes de ipêroxo (Tabebuia impetiginosa (Mart. ex DC.) Standl.) antes do armazenamento.

\begin{tabular}{ccccc}
\hline $\mathrm{GU}(\%)$ & $\mathrm{G}(\%)$ & $\mathrm{CPA}(\mathrm{cm})$ & $\mathrm{IVE}$ & $\mathrm{E}(\%)$ \\
\hline 18,3 & $83 \mathrm{a}$ & $5,12 \mathrm{a}$ & $0,456 \mathrm{a}$ & $62 \mathrm{a}$ \\
12,5 & $82 \mathrm{a}$ & $4,86 \mathrm{a}$ & $0,455 \mathrm{a}$ & $59 \mathrm{a}$ \\
8,4 & $87 \mathrm{a}$ & $5,60 \mathrm{a}$ & $0,486 \mathrm{a}$ & $67 \mathrm{a}$ \\
4,2 & $83 \mathrm{a}$ & $4,33 \mathrm{a}$ & $0,382 \mathrm{a}$ & $64 \mathrm{a}$ \\
\hline $\mathrm{CV}(\%)$ & 14,8 & 10,9 & 11,3 & 13,7 \\
\hline
\end{tabular}

Médias seguidas de mesma letra na coluna não diferem entre si pelo teste de Tukey em $5 \%$ de probabilidade. CV - coeficiente de variação experimental.

Pelos dados das avaliações fisiológicas (Tabelas 2, 3, 4 e 5) observa-se que as sementes com graus de umidade de 12,5, 8,4 e 4,2\% mantiveram seu desempenho fisiológico no nitrogênio líquido. Por outro lado, o teor de água mais elevado $(18,3 \%)$ causou declínio na germinação, indicando ação prejudicial à conservação das sementes.

TABELA 2. Valores médios de germinação (\%) obtidos de sementes de ipês-roxos (Tabebuia impetiginosa (Mart. ex DC.) Standl.) com diferentes graus de umidade e armazenadas em nitrogênio líquido $\left(-196^{\circ} \mathrm{C}\right)$ por diferentes períodos.

\begin{tabular}{cccc}
\hline Graus de & \multicolumn{3}{c}{ Períodos de armazenamento (dias) } \\
\cline { 2 - 4 } umidade (\%) & 120 & 240 & 360 \\
\hline 18,3 & $8 \mathrm{~b}$ & $4 \mathrm{~b}$ & $10 \mathrm{~b}$ \\
12,5 & $79 \mathrm{a}$ & $78 \mathrm{a}$ & $77 \mathrm{a}$ \\
8,4 & $85 \mathrm{a}$ & $72 \mathrm{a}$ & $73 \mathrm{a}$ \\
4,2 & $77 \mathrm{a}$ & $76 \mathrm{a}$ & $67 \mathrm{a}$ \\
\hline $\mathrm{CV}(\%)$ & 13,7 & 15,5 & 11,9 \\
\hline
\end{tabular}

Médias seguidas de mesma letra na coluna não diferem entre si pelo teste de Tukey em 5\% de probabilidade. CV - coeficiente de variação experimental.
TABELA 3. Valores médios de emergência de plântulas (\%) obtidos a partir de sementes de ipêroxo (Tabebuia impetiginosa (Mart. ex DC.) Standl.) com diferentes graus de umidade e armazenadas em nitrogênio líquido $\left(-196^{\circ} \mathrm{C}\right)$ por diferentes períodos.

\begin{tabular}{cccc}
\hline Graus de & \multicolumn{3}{c}{ Períodos de armazenamento (dias) } \\
\cline { 2 - 4 } Umidade (\%) & 120 & 240 & 360 \\
\hline 18,3 & $1 \mathrm{c}$ & $0 \mathrm{~b}$ & $2 \mathrm{~b}$ \\
12,5 & $71 \mathrm{a}$ & $60 \mathrm{a}$ & $84 \mathrm{a}$ \\
8,4 & $66 \mathrm{a}$ & $60 \mathrm{a}$ & $79 \mathrm{a}$ \\
4,2 & $57 \mathrm{~b}$ & $51 \mathrm{a}$ & $76 \mathrm{a}$ \\
\hline $\mathrm{CV}(\%)$ & 15,7 & 12,5 & 10,1 \\
\hline
\end{tabular}

Médias seguidas de mesma letra na coluna não diferem entre si pelo teste de Tukey em $5 \%$ de probabilidade. CV - coeficiente de variação experimental.

TABELA 4. Valores médios de índice de velocidade de emergência de plântulas obtidos a partir de sementes de ipê-roxo (Tabebuia impetiginosa (Mart. ex DC.) Standl.) com diferentes graus de umidade e armazenadas em nitrogênio líquido $\left(-196^{\circ} \mathrm{C}\right)$ por diferentes períodos.

\begin{tabular}{cccc}
\hline Graus de & \multicolumn{3}{c}{ Períodos de armazenamento (dias) } \\
\cline { 2 - 4 } umidade (\%) & 120 & 240 & 360 \\
\hline 18,3 & $0,300 \mathrm{c}$ & $0,000 \mathrm{~b}$ & $0,033 \mathrm{~b}$ \\
12,5 & $0,581 \mathrm{a}$ & $0,410 \mathrm{a}$ & $0,587 \mathrm{a}$ \\
8,4 & $0,553 \mathrm{ab}$ & $0,482 \mathrm{a}$ & $0,545 \mathrm{a}$ \\
4,2 & $0,436 \mathrm{~b}$ & $0,347 \mathrm{a}$ & $0,529 \mathrm{a}$ \\
\hline $\mathrm{CV}(\%)$ & 15,3 & 18,1 & 14,7 \\
\hline
\end{tabular}

Médias seguidas de mesma letra na coluna não diferem entre si pelo teste de Tukey em $5 \%$ de probabilidade. CV - coeficiente de variação experimental.

Esses resultados concordam parcialmente com o relatado por Stanwood (1984), o qual afirmou que o teor de água das sementes, após secagem para serem submetidas à preservação do potencial fisiológico em nitrogênio líquido, deve estar entre 4 e 7\%. Da mesma maneira, sementes de aroeira (Astronium urundeuva (Fr. All.) Engl.) desidratadas até $6 \%$ podem ser imersas diretamente em nitrogênio líquido e conservadas pelo método de criopreservação (Medeiros e Cavallari, 1992); também, Wetzel et al. (2003) observaram 
em sementes de Tabebuia umbellata (Sond.) Sandw., com teor de água inicial de $8,9 \%$ e de $6,0 \%$ após secagem, e imersas em nitrogênio líquido, germinação de 66 e $75 \%$, respectivamente.

TABELA 5. Valores médios de comprimento da parte aérea $(\mathrm{cm})$ de plântulas obtidas a partir de sementes de ipê-roxo (Tabebuia impetiginosa (Mart. ex DC.) Standl.) com diferentes graus de umidade e armazenadas em nitrogênio líquido $\left(-196^{\circ} \mathrm{C}\right)$ por diferentes períodos.

\begin{tabular}{cccc}
\hline Graus de & \multicolumn{3}{c}{ Períodos de armazenamento (dias) } \\
\cline { 2 - 4 } umidade (\%) & 120 & 240 & 360 \\
\hline 18,3 & $0,168 \mathrm{c}$ & $0,000 \mathrm{~b}$ & $0,520 \mathrm{c}$ \\
12,5 & $6,556 \mathrm{ab}$ & $3,571 \mathrm{a}$ & $9,280 \mathrm{a}$ \\
8,4 & $6,835 \mathrm{a}$ & $3,863 \mathrm{a}$ & $8,392 \mathrm{ab}$ \\
4,2 & $4,627 \mathrm{~b}$ & $2,913 \mathrm{a}$ & $7,415 \mathrm{~b}$ \\
\hline $\mathrm{CV}(\%)$ & 18,8 & 18,6 & 17,8 \\
\hline
\end{tabular}

Médias seguidas de mesma letra na coluna não diferem entre si pelo teste de Tukey em $5 \%$ de probabilidade. CV - coeficiente de variação experimental.

$\mathrm{O}$ fato das sementes não perderem qualidade fisiológica, quando em contato com nitrogênio líquido $\left(-196^{\circ} \mathrm{C}\right)$ é explicado por Stanwood e Roos (1979). De acordo com esses pesquisadores, sementes ortodoxas podem ser desidratadas a um grau de umidade muito baixo sem a ocorrência de danos por congelamento ou por formação de cristais de gelo, e sem prejuízo à viabilidade. Isto é essencial para o sucesso da criopreservação, pois os danos pela dessecação parecem ser insignificantes.

\section{CONCLUSÕES}

As sementes de ipê-roxo (Tabebuia impetiginosa (Mart. ex DC.) Standl) podem ser previamente desidratadas a $4,2 \%$ de água e posteriormente imersas em nitrogênio líquido por, pelo menos, 360 dias sem redução na qualidade fisiológica.

\section{REFERÊNCIAS}

BEWLEY, J.D.; BLACK, M. Seeds: physiology of development and germination. New York: Plenum Press, 1984. p.377-416.
BRASIL. Ministério da Agricultura e Reforma Agrária. Regras para análise de sementes. Brasília, DF: SNDA/ DNDV/CLAV, 1992. 365p.

CROMARTY, A.S.; ELLIS, R.H.; ROBERTS, E.H. Design of seed storage facilities for genetic conservation. Rome: International Board of Plant Genetic Resources, 1985. $100 \mathrm{p}$.

ETTORI, L.C.; SIQUEIRA, A.C.M.F.; SATO, A.S.; CAMPOS, O.R. Variabilidade genética em populações de ipê-roxo - Tabebuia heptaphylla (Vell.) Tol. - para conservação ex situ. Revista do Instituto Florestal, v.8, n.1, p.61-70, jul.1996.

HARRINGTON, J.F. Seed storage and longevity. In: KOSLOWSKI, T.T. Seed biology. New York: Academic Press, v.3, p.145-245. 1972.

IBPGR. INTERNATIONAL BOARD FOR PLANT GENETIC RESOURCES. The design of seed storage facilities for genetic conservation. Rome: IBPGR, 1982. 95p.

INTERNATIONAL SEED TESTING ASSOCIATION. Rules for seed testing. Zurich, 2007. n.p.

KARTHA, K.K. (Ed.). Cryopreservation of plant cell and organs. Boca Raton: CRC Press Inc, 1985. 276p.

LONGHI, R.A. Livro das árvores: árvores e arvoretas do Sul. 2.ed. Porto Alegre: L\&PM, 1995. 176p.

LORENZI, H. Árvores brasileiras: manual de identificação e cultivo de plantas arbóreas nativas do Brasil. 4. ed. Nova Odessa: Editora Plantarum, 2002. v.1, p.66.

MAGUIRE, J.D. Speed of germination aid in selection and evaluation for seedling emergence and vigor. Crop Science, v.2, p.176-177. 1962.

MARCOS FILHO, J.; CÍCERO, S.M.; SILVA, W.R. Avaliação da qualidade das sementes. Piracicaba: FEALQ, 1987. 230p.

MARTINS, L.; SILVA, W.R.; LAGO, A.A. Conservação de sementes de tangerina 'Cleópatra': teor de água e temperatura do ambiente. Revista Brasileira de Sementes, v.29, n.1, p.178-185, 2007.

MEDEIROS, A.C.S.; CAVALLARI, D.A.N. Conservação de germoplasma de aroeira (Astronium urundeuva (Fr. All.) Engl. I. Germinação de sementes após imersão em nitrogênio líquido $\left(-196^{\circ} \mathrm{C}\right)$. Revista Brasileira de Sementes, DF, v.14, n.1, p.73-75, 1992.

REIS, A.M.M.; CUNHA, R. Efeito do congelamento sobre a viabilidade de sementes de Anadenanthera peregrina 
(L.) Speg. com diferentes conteúdos de umidade. Pesquisa Agropecuária Brasileira, v.32, n.10, p.1-12, 1997.

SIQUEIRA, A.C.M.F.; NOGUEIRA, J.C.B. Essências brasileiras e sua conservação genética no Instituto Florestal de São Paulo. Revista do Instituto Florestal, v.4, n.4, p.1187, 1992. Edição dos Anais do CONGRESSO NACIONAL SOBRE ESSÊNCIAS NATIVAS, São Paulo, 1992. Edição especial.

STANWOOD, P.C.; ROSS, E.E. Seed storage of several horticultural species in liquid nitrogen $\left(-196^{\circ} \mathrm{C}\right)$. Horticultural Science, v.14, n.5, p.628-630, 1979.

STANWOOD, P.C. Cryopreservation of seeds: a preliminary guide to the practical preservation of seed germoplasm in liquid nitrogen. In: FAO. International Board for Plant Resources. IBPGR Advisory Committee on Seed Storage. Roma, 1984, p. 8-27.
STOCKMAN, A.L.; BRANCALION, P.H.S.; NOVEMBRE, A.D.L.C.; CHAMMA, H.M.C.P. Sementes de ipê-branco (Tabebuia roseo-alba (Ridl.) Sand. - Bignoniaceae): temperatura e substrato para o teste de germinação. Revista Brasileira de Sementes, v.29, n.3, p.121-125, 2007.

VANZOLINI, S.; ARAKI, C.A.S.; SILVA, A.C.T.M.; NAKAGAWA, J. Teste de comprimento de plântulas na avaliação da qualidade de sementes de soja. Revista Brasileira de Sementes, v.29, n.2, p.90-96, 2007.

WETZEL, M.M.V.S.; REIS, R.B.; RAMOS, K.M. Metodologia para criopreservação de sementes de espécies florestais nativas. Brasília, DF: Embrapa Recursos Genéticos e Biotecnologia, 2003, 5p. (Embrapa Recursos Genéticos e Biotecnologia. Circular Técnica, 26). 